\title{
Pedagogía de la memoria desde las voces de los agentes
}

José ARLÉS GóMEZ ARÉVALO*

La paz verdadera solo se encuentra en la realidad de la existencia cotidiana. Debemos plantar las semillas de una paz fundamental en la vida diaria de los individuos y en lo más recóndito de nuestro interior. Tenemos que proteger y nutrir esas simientes hasta que se conviertan en la realidad concreta de una paz para todos.

DAISAKU IKEDA

\section{Introducción}

Pese a los avances realizados en años anteriores en América Latina y en Colombia relacionados con la consolidación de una pedagogía de la memoria, aún falta bastante camino por recorrer en términos de su fundamentación epistemológica, referida a los lineamientos educativos,

* Director del Doctorado en Educación de la Universidad Santo Tomás. Posdoctor en Ciencia y Narrativa de la Universidad de Córdoba, Argentina; PhD en Teología de la Universidad Pontificia Urbaniana, Roma; magíster en Filosofía y especialista en Educación-Filosofía Colombiana de la Universidad Santo Tomás; especialista en Orientación Sexual de la Universidad Manuela Beltrán, y licenciado en Teología de la Pontificia Universidad Javeriana. Coordinador del grupo de investigación Ciencia, Pedagogía y Espiritualidad. 
pedagógicos y didácticos que deben respaldarla y realizarla, en el sentido de convertirla en un medio importante para crear ambientes y culturas de convivencia y de paz.

Así, pensar en una pedagogía de la memoria histórica, específicamente en Colombia, implica tener presente a todos sus actores y víctimas, de manera que, al concebirla como un espacio de diálogo de diferentes visiones sobre el pasado y sus repercusiones en el presente y futuro del país, convenga en una visión más amplia, objetiva y honesta: releer las historias de vida, de construcción y significación colectiva de quienes hemos vivido los efectos del horror y las consecuencias de la guerra de manera directa o indirecta.

Teniendo claro que los fundamentos epistemológicos relacionados con una pedagogía de la memoria, aún están por construirse desde sus referentes educativos, didácticos, pedagógicos, es importante decir que esta propuesta opta por un modelo holístico como posibilidad de intersección de miradas pedagógicas, posturas educativas y de integración de saberes y conocimientos que articulan un campo específico de trabajo académico: la memoria histórica y su posibilidad de pedagogización en el campo de la educación superior.

En este sentido, estructurar un proyecto que involucre la pedagogía de la memoria desde las voces de sus agentes, significa apostar por la articulación y la retroalimentación de diversas perspectivas sobre la institución, la memoria y el conflicto; temas que abarcan las dimensiones jurídica, histórica, sociológica, antropológica, politológica, psicológica y filosófica de una de nuestras instituciones estatales más representativas y admiradas por su aporte al país.

La presente propuesta de una pedagogía de la memoria desde las voces de agentes, testigos e intérpretes, busca contribuir en la generación de una mirada profunda y compleja de los fenómenos que se estudian alrededor de la categoría memoria histórica, así como constituirse en un soporte, desde la investigación social, para la construcción de nuevas miradas sobre la memoria en la historia presente y futura de un país complejo y paradójico como lo es Colombia. Con este capítulo se quiere aportar algunos elementos para entender el sentido que se le puede dar pedagógicamente al fundamento de la confrontación 
armada, sus posibilidades de aprehensión y entendimiento, teniendo en cuenta las diferentes voces que aportan a la reconstrucción de los sucesos acaecidos y sus consecuencias en el gran escenario de la cultura, la política y la sociedad colombiana. De esta manera, el presente trabajo puede ser un aporte para la relectura de múltiples relatos sobre la memoria histórica de este país, haciendo propuestas para la creación de una cultura de la paz a partir de la cual, entendiendo los orígenes y las razones de esos estados de guerra, se pueda entrar en una etapa de reconciliación.

\section{Antecedentes}

En los últimos años, en varios países de América Latina, las políticas públicas modificaron los currículos por medio de nuevas legislaciones que pasaron a exigir la incorporación de ciertos contenidos y el estudio del pasado reciente - especialmente en aquellos países donde se vivieron experiencias duras y sangrientas de dictadura militar-con el fin de promover la educación para el nunca más, para no repetir. De esta manera, en la última década especialmente se han desarrollado diferentes formas y espacios que ayudan a ahondar en la memoria, tales como museos, lugares de la memoria, recordación de fechas, películas, canciones y diferentes manifestaciones culturales que visibilizan y colaboran con el trabajo pedagógico.

Algunas visiones llegan a identificar una especie de inflación de la memoria; más allá de esta interpretación, es importante considerar esta expansión como una respuesta a uno de los problemas de la cultura contemporánea neoliberal, que es silenciar el pasado, entendido este como un peso que se lleva a cuestas y no, en cambio, como una corriente de vida, importante para que se construyan nuevos sentidos.

Por otra parte, en las últimas décadas el tema de la memoria se ha constituido en uno de los más acuciantes en la agenda pública, pautado por un momento histórico en el cual predomina la sensación de un presente que se escapa vertiginoso y cuyas líneas de continuidad con el pasado y el futuro parecen estar cada vez más desdibujadas. Ello 
ha traído como contraparte un sinnúmero de iniciativas con las que se pretende rescatar las memorias de actores y protagonistas de acontecimientos de la historia reciente, dentro de las cuales se inscribe el interés no solo por la narrativa o literatura testimonial, sino, cada vez más, por la pedagogía de la memoria y la enseñanza de esa historia reciente, tanto de los países Latinoamericanos, como de algunos europeos, asiáticos y africanos que ven marcada su historia por la violencia política, el genocidio y la vulneración de derechos humanos.

De la misma manera, a nivel latinoamericano, en el marco de las dictaduras o "democracias restringidas", encontramos, entre otras, dos realidades: la primera es que buena parte de la producción narrativa ha estado motivada por la necesidad de denuncia y esclarecimiento de los vejámenes ocurridos, y la segunda, que esta ha tenido la urgencia de encontrar posibilidades de recomponer sus historias socioculturales, con miras a que hechos como los que las afectan tanto nunca se vuelvan a repetir, porque se tiene que aprender de esas huellas de dolor que nos ha dejado el siglo xx y del significado de experiencias límite de terror y represión para sociedades concretas y para la humanidad en general.

De lo anterior se desprende que hablar de una pedagogía de la memoria como posibilidad y necesidad nos permite identificar, a través de las narrativas de estas mismas realidades, aquellos procesos que admitan abrir las puertas del dolor en el presente con miras a reconfigurar el futuro, reconstituyendo y validando una memoria crítica, empoderada y pública. Esta memoria se configuraría, ya no desde un dolor impotente, sino desde un proyecto serio y estructurado que camine hacia la reparación integral desde el marco del derecho fundamental a la existencia. Así, se espera que, como el deseo a la memoria misma, esta pedagogía de la memoria se fundamente en "una consideración humana y temporalizada del sujeto constructor de significados con otros, [y] pueda facilitar los espacios para expresar las configuraciones de las identidades en devenir, devenir humano y justo como memoria cultural y memoria comunicativa" (Osorio, 2006, p. 29).

Bajo esta panorámica, el presente apartado desea, además, mostrar algunas reflexiones sobre el auge de la memoria, algunos puntos 
de debate al respecto, su interés para la historia cultural de la educación, así como las preocupaciones actuales. En la segunda mitad del siglo $\mathrm{xx}$, diversas esferas sociales y de conocimiento vuelcan su interés en las modificaciones en la experiencia de la temporalidad humana: hay una eclosión de movimientos sociales y procesos de descolonización, discusiones sobre el genocidio nazi y acontecimientos históricos a él asociados, entre otros hechos históricos de distintas partes del mundo, incluso del continente latinoamericano.

Andreas Huyssen (2007) plantea que en las inquietudes contemporáneas por la memoria:

lo que está en cuestión es una transformación lenta pero tangible de la temporalidad que tiene lugar en nuestras vidas y que se produce, fundamentalmente, a través de la compleja interacción de fenómenos tales como los cambios tecnológicos, los medios masivos de comunicación, los nuevos patrones de consumo y la movilidad global. (pp. 28-29)

Estos fenómenos han dotado de profunda inestabilidad el tiempo y fracturado el espacio, en contraste con como eran percibidos en los siglos antecedentes al proyecto de la modernidad. Lo anterior ha traído, como contraparte, el miedo al olvido, que ha tratado de ser conjurado a través de múltiples estrategias de recuperación de la memoria, consistentes en erigir recordatorios públicos y privados (Huyssen, 2007).

Con el objetivo de fortalecer la propuesta sobre la pedagogía de la memoria, a continuación se presentan algunos antecedentes relacionados con el tema central. Acuña Méndez (2009) fundamenta el análisis de experiencias de educación para la paz en el contexto de América Latina. De estas experiencias sobresalen cinco puntos fundamentales que fueron los ejes centrales del análisis: orígenes de las experiencias, objetivos dentro de cada una, postulados teóricos, estrategias y potencial pedagógico identificado y las lecciones aprendidas en cada caso. Esta investigación realizó la selección de nueve experiencias, las cuales presentaban la información más significativa para hacer un mejor 
análisis; no obstante, se hace urgente y necesario, de cara al posacuerdo, repensar los fundamentos de una educación y una pedagogía para la formación de la memoria histórica.

Asimismo, el CNMH (Centro Nacional de Memoria Histórica), entidad creada en Colombia por la Ley 1448 de 2011 con la finalidad de, entre otras, promover la construcción de memoria histórica, se enfrenta al reto de llevar a cabo una construcción de experiencia nunca antes vivida en el mundo, habida cuenta de que, en primer lugar, la memoria histórica no ha sido abordada de manera tan integral como lo ordena la mencionada ley y, en segundo lugar, el CNMH tiene el reto de construir memoria histórica en medio de un conflicto armado aún sin resolver. En ese sentido, la presente propuesta ofrece la posibilidad de analizar la experiencia de muchas personas que han sufrido las consecuencias del conflicto armado, e identificar los elementos que han arrojado resultados positivos en otros países respecto a la construcción de memoria histórica, lo cual puede redundar en el diseño de otras experiencias pedagógicas para la construcción de memoria histórica de manera incluyente, pero ante todo efectiva en su fin último de divulgación y apropiación por la sociedad y las nuevas generaciones.

Por otro lado, es importante reconocer que Colombia no es el primer ni el último país que sufre un conflicto armado y que resulta fundamental comprender cómo los procesos educativos que han emprendido otros países pueden ser útiles, aplicables, transferibles o no al escenario colombiano, sea en medio del conflicto armado o del posconflicto. Se entiende, por supuesto, que cada caso en el mundo tiene particularidades que obedecen a la historia y situación de cada país.

De igual manera, es de mencionar el artículo de Aguirre (2015) titulado “¿Por qué es importante la memoria histórica en Colombia?”, en el cual se aborda el proceso transicional que vivimos en la actualidad. Desde la teoría de la justicia transicional, Aguirre considera este proceso como uno de los más íntegros, pues en él se tiene en cuenta el papel ocupado tanto por víctimas como por victimarios. Cabe señalar también que la ley busca reivindicar a las víctimas al tratar los derechos de verdad, justicia y reparación, lo cual, según manifiesta Aguirre, favorece la mirada de la sociedad colombiana en general. En el artículo 
se destaca no solo la importancia sino la necesidad de crear una memoria histórica que permanezca en el tiempo y permita a la sociedad tener conocimiento de su historia, por lo tanto, invita a la construcción de una memoria colectiva, que facilite la creación de un lenguaje con su significación, común a todos los actores de la sociedad, para dar lugar a la construcción colectiva de su identidad.

Aguirre (2015) resalta la necesidad del esclarecimiento de los hechos, de no olvidar las masacres ocurridas como las de El Salado, Mapiripán, Bojayá o Jamundí, entre otras, las cuales, a la fecha, solamente son recordadas por aquellas personas que sobrevivieron a los hechos. Ante esto, asegura que el recuerdo y la representación de estos hechos no necesariamente tienen que corresponder solo a las víctimas y a los responsables directos; de hecho, es un derecho que tienen todos los colombianos de conocer la verdad de lo ocurrido, como una garantía de que no se volverá a repetir.

En este orden de ideas, la autora afirma que para la construcción de la memoria colectiva es necesaria la participación de las víctimas, respetando su intimidad, sus testimonios y vivencias. Para ello, entonces, dice que la construcción de la memoria debe contar con varias generaciones. La primera está comprendida por los adultos mayores, quienes por su experiencia tienen mayor conocimiento del conflicto armado, esta generación entonces es importante para la memoria histórica; una segunda generación que comprende a los niños y jóvenes en edad escolar y universitaria, quienes harían aportes gracias a la educación que están recibiendo. Finalmente, una tercera generación conformada por los adultos entre 35 y 55 años, quienes aportarían desde la sensibilización, así en su mayoría no hayan sido cercanos al conflicto, pues mantendrían la esperanza de que este sea superado.

Igualmente, Aguirre (2015) señala que Colombia no es el único país que ha vivido o vive un conflicto armado interno, que existen sociedades que han superado sus conflictos por medio de procesos de transición exitosos, como el caso de Argentina y Chile en América Latina, o Alemania en Europa, que pueden brindar experiencias con el fin de evitar diferentes errores. Pero afirma que, ante todo, debe garantizarse que la memoria permanezca en el tiempo, tarea que incluye varias estrategias y herramientas. 
Asimismo, Rueda (2013), en “Memoria histórica razonada”, hace una propuesta incluyente para las víctimas del conflicto armado interno colombiano. Señala que la memoria histórica razonada, como propuesta teóricometodológica, busca la efectiva participación activa de las víctimas del conflicto armado en la construcción de la historia colombiana. "El artículo es un aporte conceptual de un estudio relacionado de trayectorias de vida de víctimas del desplazamiento forzado" (2013, p. 17) en la ciudad de Bucaramanga, y evidencia un debate teórico sobre memoria e historia entre diferentes autores de las ciencias sociales y humanas. A través de la construcción de la memoria histórica razonada, busca que se comprendan los relatos de quienes fueron desplazados, a través de un conocimiento complementario entre víctimas e investigadores. Rueda plantea que con ello se puede generar instrumentos contra las marginalidades, los negacionismos, los silencios y olvidos desarrollados por los poderes. Entre otras, llega a la conclusión de que los testimonios relatados por las víctimas pueden ser importantes para la sociedad, en cuanto sean recopilados y divulgados abiertamente, de tal manera que no sean parte de políticas del silencio y del olvido.

A nivel latinoamericano, es importante reconocer el caso del Perú en cuanto a esfuerzos por implementar una pedagogía de la memoria desde el ejercicio de los derechos fundamentales. Este país, en el 2003, conoció públicamente el Informe Final de la Comisión de la Verdad y Reconciliación en el Perú. En ese momento, el país inca empieza a tomar conciencia de los hechos de violencia y terror que se vivieron durante veinte años y, como parte de este informe, se realizó una serie de recomendaciones pedagógicas para que, en el futuro, los peruanos evitaran la repetición de los hechos que tanto dolor causaron al país. Concretamente, se vio la necesidad de trabajar los temas de memoria histórica y derechos humanos con la sociedad civil. Reconstruir la memoria colectiva en diversos sectores de este país se convirtió en una prioridad, ya que facilitaría no solo la recuperación de la confianza en las instituciones, sino en los demás, y reforzaría el trabajo por un nuevo orden más democrático, justo y solidario.

Otro caso concreto en el que se intentó establecer una pedagogía de la memoria histórica es el de Guatemala. Este país, en términos 
generales, no había tenido la oportunidad de procesar su historia y lo sucedido durante el conflicto armado interno que duró 36 años, de 1963 a 1996, y que afectó a toda la población. Según algunos informes de la Comisión para el Esclarecimiento Histórico, fueron más de 300000 las personas asesinadas, además de un elevado número de personas refugiadas, desplazadas internas y víctimas de violencia sexual y psicológica. En el proceso de establecimiento de parámetros concretos y líneas de acción, muchos investigadores se dieron cuenta de que tanto la niñez como la juventud guatemalteca no conocían lo sucedido, lo cual contribuyó a que la violencia como paradigma estuviera ausente de los discursos y de las relaciones sociales. De ahí la relevancia que cobró el abordaje de la memoria histórica en el mencionado país centroamericano, era necesario renombrar lo sucedido y resignificar la historia, con el fin de evitar que las guerras se repitieran y emprender la reparación de los daños y consecuencias de las mismas. Por este motivo, se organizó un proyecto que tuvo por objeto promover una nueva convivencia basada en el respeto y en valores orientados a la construcción de la paz, así como contribuir a la dignificación de los sobrevivientes a la violencia.

En el caso de Argentina, después del nefasto periodo trascurrido entre 1976 y 1983 durante el cual desaparecieron y asesinaron a miles de personas con complicidad del gobierno militar, surgieron pequeños grupos que comenzaron a reclamar justicia y respuestas del Estado. Las familias de los desaparecidos, sus madres, evocaban su recuerdo y reclamaban la aparición de sus seres queridos. El concepto de recuerdo y memoria, en el caso argentino, surge a través de la reivindicación del pueblo, que pedía no olvidar lo que pasó, recordar para que no se volviera a repetir. Estas ideas fueron gestándose y creciendo a lo largo de muchos años en ese país, hasta la aparición de un gobierno con buena voluntad que supo interpretar ese reclamo y transformarlo en políticas públicas concretas y tangibles.

En América Latina el tema de la memoria instauró, en este tiempo, discusiones importantes en el seno de sociedades que se han dado a la tarea de revisar diversos aspectos sobre su pasado reciente (sistemas de gobierno bipartidistas, etapas de transición, instauración de democracia, etc). Colombia, que no se ajusta del todo a esta tipología, 
ha sido ajena a estas dinámicas, porque la formación de memoria, la constitución de subjetividades y los procesos de subjetivación ocurren en los distintos espacios en los que interactúan los sujetos, por ende se configuran experiencias y emergen significaciones sobre lo cultural, lo social y lo político.

Las memorias sobre la violencia política, los hechos estudiados en torno a la historia reciente de América Latina y otros países, han dejado al descubierto la vigencia de múltiples esferas de socialización y subjetivación: desde cárceles y cementerios ilegales, hasta el manejo de medios de comunicación como lugares, en cuanto que sirven de memoria informativa en la cultura. De igual manera, muchas agrupaciones políticas, redes informales, colectivos artísticos, en diversos espacios públicos de debate y confrontación, constituyen escenarios en donde confluyen de manera desordenada diversos actores, fuerzas sociales y narrativas para la conformación de las subjetividades y de las memorias sociales sobre los acontecimientos vividos y sus formas de significación, instituyéndose como reservorios de aprendizaje social del pasado reciente de nuestro continente y otros escenarios geográficos. El estudio de estos escenarios debe ser incorporado en las agendas de la investigación histórica en educación desde una perspectiva cultural.

Por otro lado, para estos antecedentes de pedagogía histórica, debe tenerse en cuenta lo que ha sucedido en los otros continentes: las transformaciones en los países comunistas del este europeo, la Unión Soviética, Sudáfrica, Ruanda, Nigeria, animados por la búsqueda de legitimaciones de los nuevos órdenes sociales, dieron pie a políticas de memoria y disputas en torno a ellas. Pero es indudable que uno de los antecedentes contemporáneos más importantes es el de la Segunda Guerra Mundial.

También se encuentran documentos y pensamientos sobre la historia en el ámbito europeo. En "El proceso de la recuperación de la 'memoria histórica' en España: una aproximación a los movimientos sociales por la memoria”, Gálvez (2006) hace un análisis sobre el fenómeno de la recuperación de la memoria histórica en dicho país estudiando los elementos que han intervenido en el proceso de reparaciones 
morales, jurídicas y económicas para las víctimas de la represión franquista. De igual manera, echa una mirada al nacimiento y consolidación del movimiento asociativo de la memoria, así como, desde una perspectiva histórica, hace un cuestionamiento sobre la manipulación del fenómeno de la memoria desde la política y los medios de comunicación. Allí, entre otras cuestiones, se concluye que es necesario emprender un estudio sobre la represión franquista durante los años cincuenta y sesenta, que permita conocer los nombres y acciones de los ejecutores de la dictadura, lo cual, de cierta manera, permitiría a cientos de personas desaparecidas y anónimas recobrar un nombre y una identidad.

Como un antecedente importante, conviene recordar el caso de la Segunda Guerra Mundial, en la que Alemania quedó dividida en dos, occidental y oriental. En el ámbito social, los ciudadanos alemanes guardaban un silencio tal que no permitía el reconocimiento de lo sucedido. La vergüenza de quienes habían sido testigos y víctimas del horror del Holocausto fue tan grande que se negaron a tomar postura y responsabilidad por ello. Este mutismo impidió no solo el acceso directo a la información de quienes habían vivido en la época de la guerra, sino que también resquebrajó los vínculos de confianza entre miembros de la familia y de la sociedad en general.

De esta forma, se inicia en Alemania un importante movimiento de reconstrucción del pasado, con el objetivo de prevenir, en el futuro, situaciones que llevaran al desarrollo de la violencia. Este proceso de reconstrucción de la memoria motivó una discusión importante sobre cómo abordarla. La pedagogía de la memoria que empezó a gestarse pasó por diversos estadios. Inicialmente tuvo rasgos moralistas y de culpabilización, lo que motivó, como era de esperarse, el rechazo de la juventud que no se sentía responsable de los acontecimientos ocurridos durante la guerra. Esta situación generó, nuevamente, una reflexión sobre cuál sería el sentido pedagógico de la memoria.

Algo importante del proceso es que los antiguos campos de concentración también formaron parte de esta discusión: ¿qué hacer con ellos?, ¿cómo resignificarlos?, ¿cómo convertirlos en espacios que generen reflexión y compromiso, y que sirvan para la no repetición de 
situaciones violentas? Todo ello provocó una serie de opiniones en todo el país, mostrando, de esta manera, la dimensión descentralizada del tema de la memoria. Es importante mencionar que los intelectuales también levantaron su voz para manifestar la importancia de abordar el tema.

En ese entonces, el punto de partida de la reflexión sobre la memoria giraba en torno a cómo abordar los temas de la guerra y del Holocausto, que representaban los crímenes más grandes que se habían cometido contra la humanidad, contra la dignidad de la persona $\mathrm{y}$, por ende, contra los derechos humanos.

En este sentido, la pedagogía de la memoria que se desarrolla en Alemania (desde diferentes espacios como la escuela, los movimientos sociales, los movimientos intelectuales y desde el Estado mismo) busca también integrar diversas situaciones de intolerancia y discriminación que se podrían suscitar en los diferentes contextos. De esta manera, se logra que la memoria no se centre únicamente en los acontecimientos del Holocausto, sino que trascienda a diversas realidades y discursos sociales. Por último, se puede decir que un aspecto importante de la reflexión sobre la memoria en Alemania tiene que ver con el tema de los derechos humanos y de cómo se garantiza su vigencia y el compromiso con los mismos.

Según las anteriores experiencias y presupuestos, la pedagogía de la memoria se proyecta como una de las posibilidades de validar lo humano en la sociedad actual, y se constituye en una respuesta crítica al orden social en "contextos políticos de significación", donde es indispensable configurar "ciudadanías memoriales", hombres y mujeres críticos, sujetos que deben, desde la memoria viva, desnudar el potencial ideológico de toda estrategia totalizadora que desee legitimar el olvido (Osorio y Rubio, 2006). Igualmente, constituye uno de los recursos efectivos contra el olvido; la pedagogía de la memoria podría ser un punto de referencia para dirigir el interés hacia la formación de una "ciudadanía memorial” (Osorio, 2006) que pueda hacer exigibles los mínimos de convivencia, en primer lugar, y ser partícipe en etapas de consolidación de cambios políticos y culturales, en la defensa y promoción de los derechos humanos y en la consolidación de una democracia real. 


\section{Referentes teóricos}

\section{Sobre el concepto de pedagogía de la memoria}

Una vez que se han asumido, en términos generales, los principales elementos de las propuestas pedagógicas de diferentes conflictos en el mundo, a continuación, se conceptualizará qué se entiende en esta propuesta por pedagogía de la memoria y, posteriormente, se explicitará por qué se optó por asumirla desde las voces de los agentes.

Haciendo un ejercicio de síntesis, se puede decir que la pedagogía de la memoria es la articulación de las prácticas referidas a los procesos de significación y apropiación de nuestra historia reciente, donde intervienen sujetos dispuestos en diferentes escenarios para la memoria. El concepto se articula con nociones referidas al rol activo de esos sujetos en el proceso de construcción del saber; con una perspectiva dialogal y circular en el uso de la palabra; con definiciones en torno a la imposibilidad de neutralidad frente a la realidad observada, conversada, resignificada; con una pedagogía de la pregunta, formulada ya hace años por Paulo Freire (2013). Además, con un concepto de memoria ejemplar en el que el pasado se convierte en principio de acción de las prácticas cotidianas, recurriendo a las lecciones de la memoria para construir nuevos horizontes de interpretación frente a las demandas que se producen hoy: ¿cómo se puede abordar en el aula y en los escenarios educativos?

Los ejes articuladores de la pedagogía de la memoria deben ser las experiencias formativas. En la etapa inicial, las actividades de recorrido por los espacios formativos, se definen como visitas guiadas para la memoria. La noción de guiado quizás sea lo primero que entra en tensión con la propuesta pedagógica, con las nociones en torno a la construcción de memorias y con el relato del espacio. Si se consultan las definiciones más generales, guiar hace referencia a ir delante mostrando el camino, conducir, dirigir a alguien, mostrar los indicios y señales. Etimológicamente, el vocablo está relacionado con cuidar, custodiar. Sin embargo, se conciben los escenarios y espacios para la memoria como espacios abiertos, abarcadores, relacionales, atentos a la dinámica de la conquista, a la contienda permanente entre memorias, olvidos 
y silencios de diferentes agentes que se disputan legitimidad, reconocimiento, saber. En este sentido, los espacios para la memoria funcionan como soporte o vehículo para la construcción de diversidad de memorias, y no como memoria en sí misma, no como algo único y estable.

La experiencia en la pedagogía de la memoria es un acontecimiento que involucra al sujeto, lo expone, lo relaciona, lo modifica. Esta noción de experiencia lleva a pensar el conocimiento del pasado reciente, no como relato literal de los acontecimientos, sino como relatos a partir de las modificaciones y transformaciones que vive el sujeto en la construcción del conocimiento y en el encuentro de memorias.

La mencionada experiencia entonces es un proceso de formación y transformación de la subjetividad, de los posicionamientos, de los sentidos comunes instalados, de las marcas que quedan en el cuerpo luego de lo que nos pasa. Hay una relación ineludible entre experiencia y condiciones de posibilidad. En este sentido, la experiencia escapa al orden de las causas y efectos, la experiencia no puede ser causada, ni cuantificados sus efectos; lo que puede hacerse es generar las condiciones para que esta se produzca: la confluencia de un momento y un espacio adecuado, un texto adecuado, subjetividad adecuada, sensibilidad adecuada.

La pedagogía de la memoria es la articulación de estos registros y complejidades, de este proceso de transmisión. La transmisión, como recuperación de memoria, es un concepto muy interesante para pensar los puentes entre la construcción de memorias y los relatos en los que se comunica. La transmisión, desde el punto de vista de los estudios en torno a la pedagogía, invita a pensar en procesos complejos, conflictivos e incompletos de vínculos intergeneracionales.

Lejos de pensar la transmisión como legado de un saber, apostamos por las posibilidades de relato entre diferentes sujetos con trayectorias y experiencias particulares, en un encuentro de sentidos donde siempre hay una pérdida, como también una apropiación, en términos de Hassoun (1996), la transformación de una herencia en tesoro. La posibilidad de la apropiación del legado, la transformación de ese relato en una pertenencia con la que sentirse parte de la historia, que deje una marca o huella, una reflexión en la subjetividad, en la identidad, es el corazón de lo que denominamos experiencia formativa. 


\section{Conceptos y enfoque pedagógico de la memoria}

Abordar la memoria con enfoque pedagógico nos lleva a verla como un elemento de aprendizaje, con el que se pretende integrar un pasado representativo con el presente y con miras a un futuro; un aprendizaje en el sentido de reconstrucción, para transformar la actitud y voluntad a favor de la colectividad, que permita convivir y participar en la construcción de una cultura de paz.

Estos procesos de reconstrucción y aprendizaje de la memoria pueden disponer de diferentes medios: las redes y grupos sociales, los grupos religiosos, los medios de comunicación masiva, el Estado, y obviamente, la institución escolar. Pero todos ellos deben cumplir con un imperativo: propiciar la búsqueda de la verdad, del origen del conflicto y de los responsables, entender sus reales causas, y siempre deberán tener el objetivo de la no repetición. Para obtener mejores resultados, si se trata de afianzar la convicción de adoptar comprensión de la memoria y una nueva actitud, es necesario utilizar el mayor número de medios posibles al ejercer esta pedagogía para la paz.

Así, uno de los primeros resultados posibles sería el desarrollo de la resiliencia, que permite a las personas erradicar, o al menos superar, el discurso de víctima en el cual muchas veces se sumergen: superar esa situación de desvalorización es una de las fortalezas del trabajo pedagógico.

Cabe agregar que, una vez analizados los contextos y situaciones de violencia, se establecerían por parte del Estado acciones de prevención y garantías para evitar la violación de derechos. Igualmente, se puede afirmar que el trabajo pedagógico de la memoria está orientado hacia el proceso de la reconstrucción de la misma, y hace que todo lo que esto implica sea un aprendizaje para una convivencia democrática.

\section{Sobre el sentido de una propuesta pedagógica en general}

Es importante establecer de entrada el sentido que posee una propuesta pedagógica, en este caso, en el ámbito de la memoria histórica. La propuesta pedagógica explica las intenciones educativas, sirve de 
guía para orientar el proceso de aprendizaje-enseñanza favoreciendo determinado tipo de interacciones entre los diferentes actores, y tiene como actor principal al estudiante en proceso de formación. La construcción de la propuesta pedagógica en una institución educativa implica la toma de decisiones sobre la manera como debe conducirse la institución con respecto al método de enseñanza, el modelo curricular, el plan formativo y, desde luego, a la concepción de enseñabilidad y educabilidad que posee la misma. Es el marco de referencia permanente de las acciones que planifica y realiza la institución para mejorar la calidad de los procesos didácticos, en especial el proceso de aprendizaje-enseñanza en un contexto específico, a fin de lograr cambios significativos en sujetos que están en proceso formativo.

Igualmente, una propuesta pedagógica concretiza el proceso de diversificación a partir de la contextualización de aprendizajes propuestos en los documentos curriculares, tanto nacionales como de la misma institución, en función de las características de los educandos y los requerimientos concretos de la institución que lidera los procesos y que se expresa a través del modelo pedagógico. Con los elementos anteriores, surge una pregunta: ¿por qué es importante una propuesta pedagógica? En términos generales, se puede afirmar lo siguiente:

- Posibilita a la comunidad educativa definir colectivamente un conjunto de principios y acciones pedagógicas que concretizan la intencionalidad del PEI (Proyecto Educativo Institucional) para lograr su finalidad básica: la formación integral de la persona humana.

- Recoge los acuerdos y criterios que orientan las decisiones que deberán tomar los profesores, organizados en equipo, para actuar en forma coordinada y dar respuesta a las demandas específicas de una realidad concreta.

- Garantiza la coherencia de la práctica educativa dentro de la institución y adecúa al contexto los documentos curriculares. Tiene en cuenta las circunstancias de esta en lo que se refiere a alumnos, docentes, recursos y otros. 
- Proporciona un marco ordenador a cada institución para lograr una actuación coordinada y eficaz de la comunidad educativa, permite responder con pertinencia a las necesidades de los alumnos e ir generando una cultura organizacional a través de valores, principios y misión compartida.

- Estimula en el docente su desarrollo personal y profesional a través del interaprendizaje y el trabajo cooperativo.

Ahora bien, para la construcción de la propuesta pedagógica, se tienen en cuenta los siguientes insumos: la identidad que comprende la visión de futuro, la misión institucional, los valores y el diagnóstico que permite identificar las fortalezas, las debilidades (análisis interno) las oportunidades y amenazas (análisis externo).

Se deben tener en cuenta los elementos del diagnóstico que se refieren al aspecto pedagógico, es decir, aquello que permite conocer las características, necesidades e intereses de aprendizaje de los estudiantes, las expectativas de los docentes, el enfoque didáctico, los métodos de enseñanza, los materiales y otros. Todo esto facilitará la toma de decisiones para mejorar el servicio educativo. En cuanto a los elementos que contiene una propuesta pedagógica, se puede decir que existen diferentes puntos de vista. Para el caso presente, se han considerado los siguientes que, como se enunciaba antes, serán asumidos desde el modelo constructivista:

- Concepciones de aprendizaje y enseñanza.

- Principios epistemológicos y educacionales.

- Principios pedagógicos y didácticos.

- Perfiles ideales de los actores educativos (directivos, docentes, estudiantes).

- Diversificación curricular.

- Demandas educativas.

- Sistema de evaluación que adopta el centro educativo. 


\section{Sobre las concepciones de enseñanza-aprendizaje}

En este punto es necesario responder a las siguientes preguntas: ¿cómo se entiende el aprendizaje? y ¿cómo se entiende la enseñanza? Para responderlas es necesario buscar en el modelo pedagógico de la institución, en el marco teóricoconceptual de la propuesta, en los lineamientos del Ministerio de Educación Nacional y en las directrices de la educación superior en el mundo. Sin embargo, la concepción de aprendizaje y enseñanza debe darse en relación con los avances de la teoría educativa en general y de los aportes del enfoque seleccionado, en este caso el modelo constructivista, siempre y cuando garantice la reconstrucción diversificada de las voces agentes de los acontecimientos de la memoria, que enfatice en el carácter no definitivo de la memoria con un carácter más dialógico o intersubjetivo del proceso enseñanza-aprendizaje, así como con los factores esenciales en la organización del conocimiento que realiza el hombre en interacción con su entorno social y natural.

\section{Fundamentos epistemológicos de la pedagogía de la memoria desde una concepción holística}

Como se expresaba en la introducción, es claro que los fundamentos epistemológicos relacionados con la construcción de una pedagogía de la memoria aún están por construirse desde sus referentes educativos, didácticos, pedagógicos. Sin embargo, esta propuesta opta por un modelo holístico en el que es posible la intersección de miradas pedagógicas, o posturas educativas, y por la integración de saberes y conocimientos que se articulan en un campo específico de trabajo académico: la memoria histórica y su posibilidad de pedagogización en la educación superior.

La educación holística aborda el desarrollo integral de la persona en el sentido más amplio, en la esfera cognitiva y en la afectiva; hace hincapié en la educación del estudiante más allá de las aulas de clase e implica pasar de un enfoque solamente cognitivo a uno más complejo, en el sentido de complexus o integral; se anima a los estudiantes a dar lo mejor de sí, se les capacita para sacar todo el potencial a las experiencias de la vida y alcanzar sus metas (Hare, 2010, p. 3). Estas 
experiencias o logros pueden ser vivencias inusuales, especiales y profundamente significativas para el individuo, o pueden representar una posición, función o vocación que la persona perciba como singular o especial, y que sea una meta importante en su vida. Así podría describirse la visión de la educación holística.

Es importante decir que la pedagogía holística no plantea una crítica a las prácticas educativas tradicionales, sino una transformación y renovación de un escenario educacional que se presenta como complejo, debido a que el estudiante de hoy es un sujeto distinto al de tiempos pasados. Igualmente expresa la necesidad de una pedagogía que apueste por la diversidad, la inclusión y la enseñanza de la no violencia. En este sentido la pedagogía holística contribuye a cambiar el discurso de las prácticas de violencia, pues postula valores y principios universales, válidos para superar los conflictos sociales.

El desafío de esta propuesta de pedagogía de la memoria desde las voces de sus agentes, consiste en la renovación de la visión educativa, con un nuevo formato, un nuevo estilo educativo, que es la pedagogía holística, y siempre con una finalidad: que tanto estudiantes como docentes puedan encarar de manera fructífera el acto educativo (de enseñanza y aprendizaje), para elevar el provecho de aquellos, no solamente en la adquisición de destrezas y conocimientos intelectuales, sino en las dimensiones que se han mencionado anteriormente.

La pedagogía holística tiene una visión multidimensional del estudiante y su planteo consiste en ver al educando como una totalidad que tiene partes que se integran y se complementan entre sí (pues hay una relación de reciprocidad entre ellas), en contraposición clara con una visión fragmentaria, consistente en apreciar al discente desde una sola y única dimensión, la intelectual, con la supremacía de esta con respecto a las demás; todas las dimensiones (física, mental, emocional y espiritual), en la pedagogía holística, tienen el mismo grado de importancia, ninguna es hegemónica. Desde esta perspectiva, la visión holística en la pedagogía implica tomar elementos de diversas escuelas y corrientes que puedan contribuir al objetivo final del proceso educativo. Para el caso de la presente propuesta, se toman elementos del enfoque pedagógico constructivista, del cognitivista y del ABP (aprendizaje basado en problemas). A continuación, se explicitan los 
elementos que se toman de cada uno de estos enfoques y, finalmente, la manera como pueden contribuir a la construcción de un campo epistemológico y educativo que fundamente la propuesta de una pedagogía de la memoria.

\section{Enfoque pedagógico constructivista}

El constructivismo es una corriente pedagógica basada en la teoría del conocimiento constructivista, que postula la necesidad de entregar al estudiante herramientas (generar andamiajes) que le permitan construir sus propios procedimientos para resolver una situación problemática, lo que implica que sus ideas se modifiquen y siga aprendiendo.

Como enfoque educativo, el constructivismo propone un paradigma donde el proceso de enseñanza se percibe y se lleva a cabo como un proceso dinámico, participativo e interactivo del sujeto, de modo que el conocimiento sea una auténtica construcción operada por la persona que aprende, por el sujeto cognoscente. El constructivismo en pedagogía se aplica como concepto didáctico en la enseñanza orientada a la acción.

Para el constructivismo la enseñanza no es una simple transmisión de conocimientos, es en cambio la organización de métodos de apoyo que permitan a los alumnos construir su propio saber. No aprendemos solo registrando en nuestro cerebro, aprendemos construyendo nuestra propia estructura cognitiva. El docente guiará al estudiante en su construcción del conocimiento e impartirá conocimientos concretos cuando sea necesario. Esta teoría está fundamentada primordialmente en tres autores, Lev Vygotsky, Jean Piaget y David Ausbel, quienes realizaron investigaciones sobre la adquisición de conocimientos en el niño.

Este enfoque como modelo pedagógico interpreta que las personas asimilan el conocimiento desde dos aspectos: 1) desde la representación inicial que se tiene de la nueva información y 2) desde la actividad externa o interna que se desarrolla al respecto.

En definitiva, todo aprendizaje constructivo supone una edificación que se realiza a través de un proceso mental que conlleva la adquisición de un conocimiento nuevo, pero en este proceso no se trata 
solo del nuevo conocimiento que se ha adquirido, sino, sobre todo, de la posibilidad de construirlo y adquirir una nueva competencia que permita generalizar, es decir, aplicar lo ya conocido a una situación nueva. El modelo constructivista, en términos generales, está centrado en la persona, en sus experiencias previas, a partir de las que realiza nuevas construcciones mentales.

El uso del método crítico-clínico en este ámbito puede favorecer mucho el conocimiento del nivel cognoscitivo del alumno, o del grado de avance o hipótesis que posee acerca de una noción operatoria o un contenido escolar. Se recomienda al maestro de una clase (sobre algún contenido o procedimiento) que antes de impartirla, vea cuidadosamente a un grupo de niños cuando aprenden, en forma individual si fuera posible, y se observe a sí mismo para conocer cómo procede a adquirir ese conocimiento que desea enseñar.

Lo anterior redunda tanto en un manejo más sensible del método (instrumento indispensable para la exploración y el entendimiento del nivel operatorio de los alumnos), como en una comprensión más fina del acto individual del aprendizaje. Otras sugerencias concretas para el maestro serían:

- Conocer las características de los estadios del desarrollo cognitivo y analizar los contenidos escolares tan cercanamente como sea posible a aquellos. Esta consideración debe tomarse con un cierto grado de laxitud.

- En educación básica es conveniente empezar la enseñanza con objetos concretos, y a partir de ellos construir paulatinamente los conceptos hasta llegar a los más abstractos.

- Varios autores han propuesto que la situación instruccional debe verse guiada por ciclos que inician en actividades de descubrimiento, en las que los estudiantes interactúan libremente con los objetos según sus concepciones espontáneas, para pasar de manera sucesiva a fases de formalización o de confrontación con un saber más institucionalizado. 


\section{Enfoque pedagógico cognitivista}

El cognitivismo incluye todas aquellas teorías que se centran en el estudio de la mente humana para comprender cómo interpreta, procesa y almacena la información en la memoria. Es decir, el objetivo principal del cognitivismo es descubrir cómo la mente es capaz de pensar y aprender. Este enfoque asume que el aprendizaje se produce a partir de la experiencia, pero, a diferencia del conductismo, lo concibe no como un simple traslado de la realidad, sino como una representación de dicha realidad. Así pues, es de vital importancia descubrir el modo en que se adquieren tales representaciones del mundo, se almacenan y se recuperan de la memoria o estructura cognitiva.

Se conoce a Jerome Brunner como el impulsor de la corriente cognitiva. Su teoría cognitiva del descubrimiento desarrolla, entre otras, la idea de andamiaje, la cual retoma de la teoría sociohistórica de Lev Vygotsky. Sus trabajos más importantes se centran en la complejización del modelo cognitivo, en la que el pensamiento y la construcción de un modelo alternativo se contemplan como el establecimiento del pensamiento humano, que es regulado por la cognición.

El aprendizaje consiste esencialmente en la categorización de nuevos conceptos, que ocurre para simplificar la interacción con la realidad y facilitar la acción. La categorización está estrechamente relacionada con procesos como la selección de información, la generación de proposiciones, la simplificación, la toma de decisiones y la construcción y verificación de hipótesis. El aprendiz interactúa con la realidad, organizando las entradas según sus propias categorías, posiblemente creando nuevas o modificando las preexistentes. Las categorías determinan distintos conceptos. Es por todo esto que el aprendizaje es un proceso activo, de asociación y construcción.

Otro supuesto es que la estructura cognitiva previa del aprendiz (sus modelos mentales y esquemas) es un factor esencial en el aprendizaje, esta da significación y organización a sus experiencias y le permite ir más allá de la información dada, ya que para integrarla a su estructura debe contextualizarla y profundizarla.

Para formar una categoría se pueden seguir estas reglas: 1) definir los atributos esenciales de sus miembros, incluyendo sus 
componentes esenciales, 2) describir cómo deben estar integrados sus componentes esenciales y 3 ) definir los límites de tolerancia de los distintos atributos para que un miembro pertenezca a la categoría.

Según el paradigma cognitivo, los dos principales objetivos de la educación deberían ser: a) lograr el aprendizaje significativo con sentido y b) desarrollar habilidades estratégicas generales y específicas de aprendizaje.

El rol del docente parte de la idea de que existe un alumno activo que aprende significativamente, que puede aprender a aprender y a pensar. El docente se centra especialmente en la confección y la organización de experiencias didácticas para lograr esos fines. No debe desempeñar el papel de protagonista en detrimento de la participación cognitiva de sus alumnos. Como se muestra en el gráfico siguiente, una enseñanza reproductiva o repetitiva genera un estudiante pasivo, que solo recibe y repite.

Figura 1. Enseñanza reproductiva y enseñanza productiva

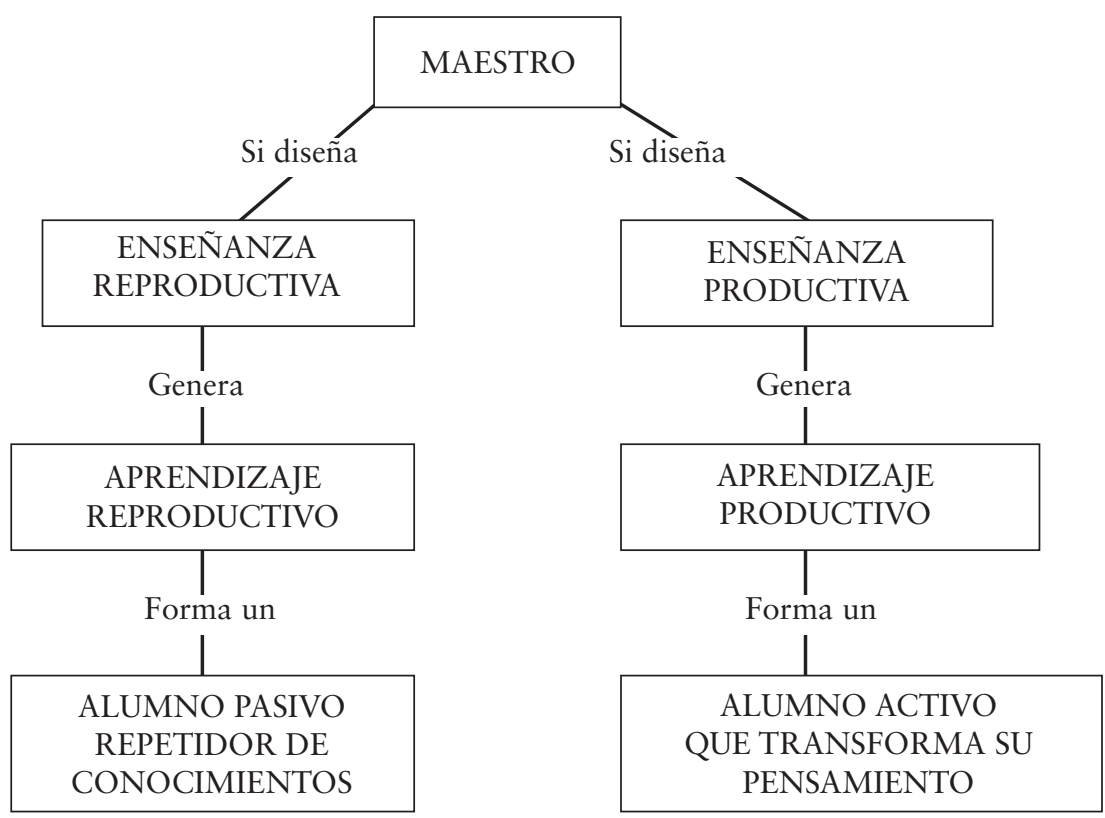


Por su parte, el estudiante es un sujeto activo, procesador de información, que posee competencia cognitiva para aprender y solucionar problemas; esta competencia, a su vez, debe ser considerada y desarrollada usando nuevos aprendizajes y habilidades estratégicas.

Con la aparición del cognitivismo, la evaluación sufre algunos cambios importantes respecto al modelo conductista, aunque su función principal se mantiene: la evaluación formativa asegura la articulación entre las características de los alumnos y las del sistema de formación.

No obstante, a continuación, se destacan algunos de los cambios más significativos:

- El interés se centra en los procesos de aprendizaje, no en los resultados obtenidos, ya que lo que se pretende es comprender el funcionamiento mental del alumno ante la tarea, a través del conocimiento de sus representaciones y de las estrategias que utiliza.

- Los datos recogidos son cualitativos: se utilizan cuestionarios, observación del comportamiento, observación de sus reflexiones y de las interacciones.

- Se da mayor importancia a las estrategias que utiliza el alumno para alcanzar un objetivo, que no al grado en que este se alcanza.

\section{Aprendizaje basado en problemas}

Es una metodología en la que, en variados grados de agenciamiento, el desarrollo del proceso de aprendizaje pone al estudiante, si no a plantearse los problemas, sí a resolver los que le deja el profesor. Sin embargo, esto es relativo al grado de originalidad y participación efectiva en la construcción del conocimiento.

\section{Otros instrumentos de aprendizaje: la aplicación de las TIC}

El uso de las Tic ha supuesto una aplicación diferente del espacio de aprendizaje y de la construcción del conocimiento. Además, ha favorecido la participación de los estudiantes de una manera más activa. 
Así pues, el uso de las TIC permite crear programas y sistemas en donde el estudiante debe no solo dar una respuesta, sino que también debe resolver problemas y tomar decisiones, lo cual contribuye al desarrollo de sus capacidades cognitivas.

A continuación, nos centraremos en algunas de las aportaciones más relevantes de autores cognitivistas con relación a la integración de las TIC en los procesos de aprendizaje:

- Interacción entre estudiantes según el cognitivismo: este paradigma considera que la interacción entre los estudiantes es un elemento básico en el proceso de aprendizaje ya que permite compartir, interactuar y observar al otro, de tal manera que esta relación facilite construir el propio conocimiento.

- Relación docente-estudiante: la relación entre el docente y el alumno se basa en la importancia de la retroalimentación como guía y apoyo a las conexiones mentales exactas. Así pues, cabe destacar dos elementos clave que favorecen el proceso de aprendizaje:

- Énfasis en la participación del estudiante en su propio proceso de aprendizaje.

- Creación por parte del docente de un ambiente de aprendizaje que permita y estimule a los estudiantes a hacer conexiones con material ya aprendido.

\section{Propuesta pedagógica}

Una vez realizado el anterior recorrido, en donde se ha colocado en evidencia la importancia de tener claro un modelo pedagógico (en este caso holístico con apoyo de los enfoques constructivista, cognitivista y del ABP), además de tener presente la misión-visión de la institución y de su modelo pedagógico en particular con todos sus componentes, se pasa a realizar la propuesta de una pedagogía de la memoria desde las voces de los agentes. 
La baja incorporación de acciones pedagógicas en la construcción de memoria histórica del conflicto armado en Colombia se debe a múltiples factores, entre los que se cuentan:

- La inexistencia de precedentes pedagógicos que permitan profundizar en experiencias previas en Colombia para construir paz desde las aulas.

- No existe suficiente experiencia institucional en la pedagogía de los derechos humanos, ni en la construcción y difusión de la memoria del conflicto armado.

- La ausencia de identificación y análisis de precedentes provenientes de otros procesos de paz.

Por otro lado, aunque se reconocen grandiosos esfuerzos del Estado y organizaciones de la sociedad civil en la implementación de acciones en materia de memoria histórica, han pasado varios años desde la promulgación de la Ley 1448 de 2011, norma que regula la materia, y las acciones pedagógicas implementadas hasta el momento no cuentan con una medición que indique cuál ha sido su impacto real. Sin embargo, resulta notorio que estas acciones han sido poco difundidas y, en general, no se ha incluido en ellas los esfuerzos de la sociedad civil; en efecto, han tenido un alcance que se limita a las mismas víctimas y a los defensores de sus derechos. Esto, por supuesto, contradice el concepto mismo de la memoria histórica y la dignificación de las víctimas, que busca que la sociedad en general conozca los hechos que tuvieron que vivir y, ante todo, las razones por las que ocurrieron.

De esta manera, al crearse la posibilidad de una pedagogía de la memoria, se estará dando importancia al enorme papel que desempeña la educación como uno de los pilares fundamentales de transformación del tejido social en Colombia y en el entorno local e internacional (lo "glocal"), asumiendo los retos y desafíos del mundo contemporáneo, fuertemente condicionado por una nueva forma de hacer presencia educativa y pedagógica.

Desde la perspectiva pedagógica, se articularon tres ejes de trabajo: 1) el proceso de formación con profesores y estudiantes de educación 
básica, con el que se pretende generar aprendizajes, a la vez que dotarlos de herramientas conceptuales y metodológicas que les permitan abordar, como temática dentro del proceso educativo, la memoria histórica vinculada a la guerra y a la violencia en general. Se contribuye de esta manera a la no repetición de la guerra, y a la creación de condiciones para vivir en paz y armonía, que incluyan a la población vulnerable por razones étnicas, de género y demás; 2) la elaboración de guías didácticas para profesorado y alumnado: se producirían guías didácticas dirigidas a los tres niveles de educación básica y adaptadas a los diferentes contextos y 3) sensibilización social sobre la memoria histórica y la violencia sexual en contra de las mujeres: para ello se realizarían actividades dirigidas a la sociedad en general, con el propósito de acabar con la estigmatización social que existe sobre las mujeres sobrevivientes de violencia sexual, rompiendo el silencio y contribuyendo a su dignificación. Entre estas actividades se realizarían festivales por la memoria de las mujeres en la guerra.

Las investigaciones de los autores mencionados atrás y los procedimientos mencionados permiten comprender la importancia de ver el conflicto desde la voz de las víctimas. Algunos documentos señalan también la importancia de la voz y participación de los victimarios, sin embargo no se encuentran elementos fuertes que permitan evidenciar la voz militar en la memoria histórica, la voz de los policías y militares, quienes en su mayoría son padres y esposos de familia, hombres y mujeres que también han perdido seres queridos, y que, por la amplia experiencia, pueden aportar de manera significativa a esa construcción colectiva de la memoria histórica.

Por lo anterior, cabe señalar la importancia de constituir una pedagogía sobre memoria histórica, pues se puede convertir en una estrategia que no solo oriente un diagnóstico, sino que además oriente acciones ordenadas desde lo institucional y pedagógico, involucrando a diferentes actores y víctimas, incluso del ámbito militar, y creando grupos de investigadores que proyecten alternativas de solución a las diferentes debilidades o necesidades que se puedan visualizar en relación con la memoria histórica. 


\section{Conclusiones}

Arriesgarse a estructurar una propuesta de pedagogía de la memoria desde las voces de los actores implica ciertamente, desde el ámbito educativo actual, pensar en dos cuestiones fundamentales. Por un lado, en los acontecimientos que signaron el siglo xx en el mundo y en Colombia y, por otro lado, en cómo la memoria histórica está ligada a los derechos humanos, convirtiéndose en objeto de enseñanza y de aprendizaje. Desde un enfoque holístico, hablar de una pedagogía de la memoria implica reconocer los aportes que se generan por la confluencia de diversos enfoques, modelos, paradigmas y corrientes de pensamiento pedagógico y educativo.

Igualmente, la pedagogía de la memoria debe transitar por los sucesos que caracterizaron el siglo xx y los que están marcando el ritmo del siglo XxI, en los que se observa que hay un despliegue científico e intelectual inédito que ha resultado ser uno de los más complejos de la historia de la humanidad. Esto, a la vez, indica la enorme posibilidad de tejer nuevos sentidos, rutas y proyectos encaminados a recuperar la memoria de nuestras colectividades y de nuestros pueblos.

Algunos autores mencionan que uno de los problemas cruciales de la cultura contemporánea es el enmudecimiento del pasado en tanto reservorio donde encontrar sentidos para alcanzar una vida más plena. Es decir que, aun cuando abunden los recordatorios, los sitios de memoria, los lanzamientos de fascículos históricos y los documentales, entre otros objetos, pocas veces estos logran darle vitalidad a un pasado que aparece, sobre todo, como un impedimento. Es aquí donde surge la pregunta por las soluciones creativas a las cuales estamos abocados como protagonistas de la misma historia.

De tal manera, en el desarrollo de una pedagogía de la memoria es imprescindible cuestionar el pasado, en el sentido de qué se debe recordar, para qué y de qué manera. Es así puesto que los pedagogos, por sus conocimientos específicos, tienen la función de recordar el pasado críticamente, deben cuestionarlo para que, por medio de la pedagogía de la memoria, se tenga acceso a un futuro esperanzador, que tenga más justicia que el pasado. Así se le da valor a la pedagogía de la memoria, pues se les permite a los actores del conflicto tener 
la palabra, para que sea tenida en cuenta y se trabaje a partir de ella (Rosemberg, 2010).

\section{Referencias bibliográficas}

Aguirre, Á. (2015). ¿Por qué es importante la memoria histórica en Colombia? Revista Nova et Vetera, 1(3). Recuperado de http://www. urosario.edu.co/Revista-Nova-Et-Vetera/Vol-1-Ed-3/Cultura/ Por-que-es-importante-la-memoria-historica-en-Col/

Rueda, J. F. (2013). Memoria histórica razonada. Una propuesta incluyente para las víctimas del conflicto armado interno colombiano. Revista Historelo. Revista de Historia Regional y Local, 5(10), 15-52. Recuperado de https://revistas.unal.edu.co/index.php/historelo/article/view/37088/html_1

Bruner, J. (1988). Desarrollo cognitivo y educación. Madrid: Morata.

Calveiro, P. (2006). Puentes de la Memoria: terrorismo de Estado, sociedad y militancia. Revista Lucha Armada en la Argentina, 1(1), 71-77.

Díaz, F. (1993). Aproximaciones metodológicas al currículo hacia una propuesta integral. México D. F.: Tecnología y Comunicación Educativa.

Freire, P. (2013). Hacia una pedagogía de la pregunta. Conversaciones con Antonio Faúndez. Buenos Aires: Siglo xxI.

Frigerio, G. y Diker, G. (comps.). (2004). La transmisión en las sociedades, las instituciones y los sujetos. Un concepto de la educación en acción. Buenos Aires: Novedades Educativas.

Gálvez, S. (2006). El proceso de la recuperación de la 'memoria histórica' en España: Una aproximación a los movimientos sociales por la memoria. Revista International Journal of Iberian Studies, 19(1). Recuperado de https://memoriarecuperada.ua.es/memoriarecuperada_v1/wp-content/ uploads/2012/10/Galvez_El-proceso_de_la_recuperacion_memoria.pdf

Gallegos, R. (1999). Educación Holista: Pedagogía del amor universal. México: Pax México.

Hare, J. (2010). La educación holística: una interpretación para los profesores de los programas del IB. Recuperado de https://blogs.ibo.org/ positionpapers/files/2010/10/La-educaci\%C3\%B3n-hol\%C3\%ADstica_John-Hare.pdf

Hassoun, J. (1996). Los contrabandistas de la memoria. Buenos Aires: La Flor. 
Huyssen, A. (2002). En busca del futuro perdido. México: Fondo de Cultura Económica.

Osorio, J y Rubio, G. (2006). El tiempo de los sujetos: pedagogía de la memoria y democracia. En J. Osorio y G. Rubio (eds.). El deseo de la memoria. Escritura e historia (pp. 13-51). Santiago: Escuela de políticas y humanidades. Recuperado de http://observatorioedhemfoc.hospedagemdesites.ws/observatorio/wp-content/uploads/2017/07/Anexo169_El_DeseodeLaMemoria.pdf

Palacios, J. (1985). Reflexiones en torno a las implicaciones educativas de la obra de Vygostky. Madrid: Sociedad Española de Psicología.

Rosemberg, J. (2010). Educación, memoria y derechos humanos: orientaciones pedagógicas y recomendaciones para su enseñanza. Recuperado de http://www.bnm.me.gov.ar/giga1/documentos/EL001596.pdf

Vygostsky, L. (1997). Historia del desarrollo de las funciones psíquicas superiores. La Habana: Ciencia y técnica. 